\title{
Genotypic Sensitivity to Drought and Yield Potential of Peanut
}

\author{
R. C. Nageswara Rao,* J. H. Williams, and Murari Singh
}

\begin{abstract}
It is important to understand genotype $\times$ drought pattern (timing, duration) interactions in peanut (Arachis hypogaea L.) to develop managerial and breeding strategies for improving and stabilizing yields in drought-prone areas or in environments with limited water resources. This study investigated genotypic sensitivity to various patterns of drought (yield decrease per unit of water deficit) and its relationship with yield potential (yield under nonstressed conditions) in a range of peanut genotypes grown on a medium deep Alfisol at ICRISAT center, Patancheru, A.P. India. In the first experiment, 22 peanut genotypes of similar maturity were evaluted in 12 drought patterns. Single and multiple periods of water deficits were created during various crop growth phases. In the second and third experiments, 60 and 64 genotypes were subjected to droughts during pod set and seed filling stages, respectively. When water deficit occurred during seed filling phase, genotypic yield potential accounted for approximately $90 \%$ of the variation in pod yield sensitivity to water deficits. It is unlikely, therefore, that breeders will be able to combine high yield potential with low sensitivity to drought spanning the seed-filling phase, therefore other improvement strategies are necessary. Pod yield potential accounted for less of the variation in drought sensitivity (15 to $64 \%$ ) in early and midseason droughts. For these circumstances it may be possible to identify genotypes with both high yield potential and relatively low drought sensitivity.
\end{abstract}

$P$ EANUT is a major cash crop in the semiarid tropics where it is grown mainly under rainfed conditions. Drought is a major factor limiting the yield of this crop in these regions (Gibbons, 1980). Supplementary irrigation is feasible only on a small proportion of the total arable area, so other methods of improving production must be developed. One possible alternative is to use drought tolerant or drought escaping genotypes.

Information on the response of different genotypes to various patterns of drought and exploitation of this variability is an important requirement for crop improvement in drought-prone areas. Several workers have investigated effects of drought on peanut at different stages of growth, and reached different conclusions (Boote et al., 1982). Using the genotype 28-206, Billaz and Ochs (1961) found that drought during pod setting caused more yield loss than drought during seed filling. However, Pallas et al. (1979) found that for Florunner, the seed filling phase was more sensitive to drought than was the pod-initiation phase. Nageswara Rao et al. (1985), using Robut 33-1, reported a yield advantage of 13 to $19 \%$ resulting from drought during the preflowering phase. This wide variation in the effects of drought might be due to differences in genotype, timing, and intensity of drought, as well as interactions between these factors.

Drought is a complex phenomenon with three

R.C. Nageswara Rao and J.H. Williams, Legumes Program; Murari Singh, Statistics, Int. Crops Res. Inst. for the Semi-Arid Tropics (ICRISAT), Patancheru, Andhra Pradesh 502 324, India. Submitted as Journal Article No. 627 by ICRISAT. Received 14 April 1988. *Corresponding author.

Published in Agron. J. 81:887-893 (1989). main, widely varying components: (i) timing of occurrence during the season, (ii) duration, and (iii) intensity. The extreme variability in the nature of drought has made it difficult to define plant attributes required for improved performance under drought. Plant breeders' approach of selecting genotypes for increased yield and stability in a drought-prone environment is limited by the variable nature of drought. However, as permutations of drought patterns are infinite, it is necessary to have information on the effects of various combinations of timing, intensity, and duration of drought on a range of genotypes. Because yield is the most important trait of a genotype, it is also necessary to examine the relationship between yield potential (achieved with adequate water) and the sensitivity of genotype in various patterns of drought.

The objective of this paper is to examine the relationship between genotypic sensitivity to drought and yield potential in a range of peanut genotypes under a range of drought patterns, which varied in their timing and duration.

\section{MATERIALS AND METHODS}

Three experiments were conducted at the ICRISAT Center, near Hyderabad, India $\left(17^{\circ} 32^{\prime} \mathrm{N}, 78^{\circ} 16^{\prime} \mathrm{E}\right)$ during the post-rainy season (November-April) of 1982-1983, 19841985, and 1985-1986, respectively. The peanut genotypes used in the experiments belong to subspecies fastigiata vars. fastigiata and vulgaris, and were of similar maturity (130$135 \mathrm{~d}$ in the post-rainy season at ICRISAT).

\section{Experiment 1}

Twenty-two genotypes were chosen to represent a range of responses found in a number of genotypes examined in a drought-screening program at ICRISAT Center (Nageswara Rao and Williams, 1989, unpublished data).

The experiment was conducted on a clay silt Alfisol (fine, hyperthermic Lithic Rhodustalf) with an available moistureholding capacity of $100 \mathrm{~mm}$ in $120-\mathrm{cm}$ depth. Diammonium phosphate (18:20:0) was incorporated into the soil at the rate of $100 \mathrm{~kg} \mathrm{ha}^{-1}$ during land preparation. The field was prepared into $1.2-\mathrm{m}$ wide beds, with $0.3-\mathrm{m}$ wide furrows between beds (Krantz et al., 1978). The seeds were hand sown on 6 Dec. 1982 in rows at right angles to the edge of the bed, with $30 \mathrm{~cm}$ between rows and $10 \mathrm{~cm}$ between seeds within rows. Each genotype was sown in two rows $12 \mathrm{~m}$ long reaching across eight beds; each bed forming the plots for the drought treatments.

Seeds were treated with captan' icis- $N$-[ (trichloromethyl)thio]-4 cyclohexene-1,2- dicarboximide and thiram' \{bis(dimethylthio-carbamoyl) disulphide $\}$ both at the rate of $3 \mathrm{~g} \mathrm{~kg}^{-1}$ before sowing. Alachlor ${ }^{1}$ [2-chloro-2'-6'-diethyl- $\Lambda$ : (methoxymethyl)-acetanilide] was sprayed at the rate of 1.5 $\mathrm{kg}$ a.i. ha ${ }^{-1}$ as a pre-emergence herbicide. Weeding was done by hand as necessary. Insecticides were applied as needed. The crop was uniformly irrigated using overhead sprinklers twice before $29 \mathrm{~d}$ after sowing (DAS) to ensure crop establishment and a fully charged soil-water profile. Irrigation 50 $\mathrm{mm}$ at each date) was applied at biweekly intervals in the

\footnotetext{
'Mention of commercial products of companies does not imply endorsement or recommendation by ICRISAT over others of similar nature.
} 
Table 1. Timing and duration of droughts applied in different patterns of drought $\left(P_{n}\right)$ in Exp. 1.

\begin{tabular}{|c|c|c|c|c|c|c|c|c|c|c|c|c|}
\hline \multirow[b]{2}{*}{ DASt } & \multirow[b]{2}{*}{$\mathbf{P}_{1}$} & \multirow[b]{2}{*}{$\mathbf{P}_{2}$} & \multirow[b]{2}{*}{$\mathbf{P}_{3}$} & \multicolumn{5}{|c|}{ Drought patterns } & \multirow[b]{2}{*}{$\mathbf{P}_{0}$} & \multirow[b]{2}{*}{$\mathbf{P}_{10}$} & \multirow[b]{2}{*}{$\mathbf{P}_{11}$} & \multirow[b]{2}{*}{$P_{12}$} \\
\hline & & & & $P_{4}$ & $\mathbf{P}_{5}$ & $\mathbf{P}_{0}$ & $\mathbf{P}_{9}$ & $\mathbf{P}_{\mathbf{8}}$ & & & & \\
\hline 1 & $\mathbf{U}$ & $\mathrm{U}$ & $\mathbf{U}$ & $\mathbf{U}$ & $\mathbf{U}$ & $U$ & 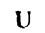 & $\mathbf{U}$ & $\mathbf{U}$ & U & $U$ & 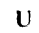 \\
\hline 15 & $\mathbf{U}$ & $\mathrm{U}$ & $\mathbf{U}$ & $\mathbf{U}$ & $\mathrm{U}$ & $\mathrm{U}$ & $\mathbf{U}$ & $\mathrm{U}$ & $\mathbf{U}$ & $\mathbf{U}$ & & 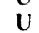 \\
\hline 29 & LS & $\mathbf{U}$ & $\mathbf{U}$ & $\mathrm{U}$ & LS & $\mathbf{U}$ & LS & LS & $\mathrm{U}$ & LS & J & LS \\
\hline 39 & LS & $\mathbf{U}$ & $\mathbf{U}$ & $\mathrm{U}$ & LS & $\mathbf{U}$ & LS & LS & $\mathbf{U}$ & LS & U & LS \\
\hline $5 i$ & LS & 11 & $\mathbf{U}$ & $\mathrm{U}$ & LS & $\mathrm{U}$ & LS & LS & $\mathbf{U}$ & LS & $\mathbf{U}$ & LS \\
\hline 57 & LS & LS & $\mathbf{U}$ & $\mathbf{U}$ & LS & $\mathbf{U}$ & LS & $\mathrm{U}$ & LS & $\mathbf{U}$ & $\mathbf{U}$ & U \\
\hline 66 & $\mathbf{U}$ & LS & $\mathrm{U}$ & $\mathbf{U}$ & LS & $\mathrm{U}$ & LS & $\mathrm{U}$ & LS & LS & LS & LS \\
\hline 72 & $\mathbf{U}$ & LS & $\mathbf{U}$ & $\mathbf{U}$ & LS & $\mathrm{U}$ & LS & $\mathrm{U}$ & LS & LS & LS & LS \\
\hline 82 & $\mathbf{U}$ & $\mathbf{U}$ & $\mathbf{U}$ & $\mathbf{U}$ & $\mathrm{U}$ & LS & LS & LS & $\mathrm{U}$ & LS & LS & LS \\
\hline 93 & $\mathbf{U}$ & $\mathbf{U}$ & LS & LS & $\mathbf{U}$ & LS & LS & LS & $\mathrm{U}$ & $\mathbf{U}$ & $\mathbf{U}$ & U \\
\hline 100 & $\mathbf{U}$ & U & LS & LS & $\mathrm{U}$ & LS & LS & LS & $\mathbf{U}$ & $\mathrm{U}$ & LS & LS \\
\hline 111 & $\mathbf{U}$ & $\mathbf{U}$ & LS & LS & $\mathbf{U}$ & LS & LS & $\mathrm{U}$ & LS & $\mathrm{U}$ & LS & LS \\
\hline 118 & $\mathbf{U}$ & $\mathbf{U}$ & $\mathbf{U}$ & LS & $\mathbf{U}$ & LS & LS & $\mathrm{U}$ & LS & $\mathrm{U}$ & LS & LS \\
\hline 129 & $\mathbf{U}$ & $\mathrm{U}$ & $\mathbf{U}$ & $\mathrm{U}$ & $\mathbf{U}$ & $\mathbf{U}$ & $\mathbf{U}$ & $\mathbf{U}$ & $\mathbf{U}$ & U & $\mathbf{U}$ & $\mathbf{U}$ \\
\hline
\end{tabular}

† DAS: Days after sowing; $U=$ Uniform irrigation using sprinklers, and LS - line-source irrigation to create eight intensities of water deficit.

beginning of the season. Frequency was increased (7- to 10d intervals) in February to match the increasing evaporative demands (Table 1).

The experiment was harvested 130 DAS. Genotypes were harvested individually from each plot (plot size $=0.9 \mathrm{~m}^{2}$ ). The number of surviving plants in each plot was recorded. The pods were separated, oven dried at $80^{\circ} \mathrm{C}$ for $48 \mathrm{~h}$, and weighed.

\section{Drought Patterns}

Twelve drought patterns were created (Table 1) to span various growth stages or combinations of growth stages. These patterns varied in two aspects; the crop growth stage(s) in which drought occurred and the total duration of deficit irrigation. Six uninterrupted droughts of variable duration were applied at different growth stages and six compound droughts were applied by alternating periods of uniform and line-source irrigation during the course of the crop's life. These included both short-term interruption of drought and longer periods of uniform irrigation. The twelve patterns of drought were assigned at random to 12 blocks in the field. Each block was divided into three replications. The 22 genotypes were randomized within each replicate.

\section{Drought Intensities within Drought Patterns}

Line-source irrrigation (Hanks et al., 1976) was used from 29 DAS to create cight drought intensities within each pattern. For each irrigation, the amount of water applied to each bed was measured at two locations in all replications using catch-cans. The bed nearest to the sprinkler line received approximately $50 \mathrm{~mm}$ of water at each irrigation, providing a control treatment within each pattern of drought. The amount of irrigation decreased in a linear fashion as the distance from the sprinkler line increased.

The water deficit (WD) was estimated for each bed using the amount of water applied during the period of drought and the cumulative class " $A$ " pan evaporation for the same period as

$$
\mathrm{WD}=100 \times(E-I / E)
$$

where WD = water deficit (\%), $E=$ cumulative pan evaporation for the period of drought, and $I=$ cumulative irrigation applied for period of drought. For multiple drought patterns, $I$ and $E$ for the component periods were summed.

Irrigation amounts given in the control plots did not satisfy $100 \%$ of class " $A$ " pan evaporation, particularly during the latter part of the season, because of the full soil profile at the start of the experiment. Thus, WD for control treat- ments was $40 \%$ in patterns that experienced drought during the second half of the season, and $20 \%$ where droughts occurred during the first half of the season.

\section{Statistical Analysis}

The control treatment yiclds (the bed nearest to the sprinkler line) allowed "site" variability associated within each block (or drought pattern) to be assessed. The yields across blocks were similar, allowing for comparison of the genotypic responses within the block.

The response of individual genotype within each drought pattern was examined by regressing pod yield against WD across the line source gradient. The regression intercept term provided the predicted yield of the genotype achieved at $0 \%$ WD. However, because WD in the adequately irrigated control ranged from 20 to $40 \%$ in different patterns, the pod yield potential of genotypes $\left(Y_{\mathrm{p}}\right)$, in the control plots, was estimated at a standard 30\% WD to avoid errors occurring from the extrapolation of the regression line beyond the range of the actual data points. The slope of the regression provided a measure of the genotypic sensitivity $\left(S_{\mathrm{d}}\right)$ to water deficits within a given drought pattern.

Univariate and bivariate analyses of variance (Wilk's criterion) (Rao, 1974) were used to evaluate the genotypic variability of $S_{\mathrm{d}}$ and $Y_{\mathrm{n}}$ within each drought pattern, and to study the genotype $\times$ drought pattern interactions. Mahalanobis' $D^{2}$ criterion (Rao, 1974) was used to group drought patterns with similar responses on the basis of regression coefficients of $S_{d}$ on $Y_{p}$

\section{Experiment 2}

Experimental site, soil characteristics, land preparation, and crop management were similar to Exp. 1. Genotypes were sown on 28 Nov. 1984 in a split-plot design with four replications in each of two main treatments (control and drought). Sixty genotypes were subplots within an irrigation treatment. Each plot was a broad bed $6 \mathrm{~m}$ long, with four rows $30 \mathrm{~cm}$ apart and $10 \mathrm{~cm}$ between seeds within a row. The crop was irrigated at 10-d intervals until the start of flowering (34 DAS), after which a drought treatment was imposed by withholding irrigation until 73 DAS. The control treatment was irrigated at $10-\mathrm{d}$ intervals during this period. After release of drought on 73 DAS, both treatments were irrigated at weekly intervals. Plots of $6 \mathrm{~m}^{2}$ were harvested on 127 DAS. Pods were picked, oven dried, and weighed. Yield loss (\%) due to midseason drought was estimated for each genotype as

$$
\% \text { yield loss }=100 \times(1-D y / W y)
$$

where, Wy is the pod yield under adequately irrigated conditions, and Dy is the pod yields in drought treatment.

\section{Experiment 3}

This experiment was conducted to study genotypic variability in sensitivity to end-of-season drought in 64 peanut genotypes (60 common to Exp. 2). These genotypes were sown on 26 Nov 1985 in a split-plot design with two main treatments (control and drought). The genotypes were arranged within the treatments in a 8 by 8 lattice design with four replications. Site, soil characteristics, land preparation, and crop management details were similar to Exp. 1. The drought treatment was imposed by withholding irrigation from 98 DAS until final harvest, while the control treatment received regular irrigations throughout the growing period. Genotypes were harvested on 131 DAS, by which time more than $75 \%$ of pods were matured in control plots. Pods were separated, oven dried, and weighed. The \% yicld loss due to drought treatment was estimated for each genotype as described in Exp. 2. 

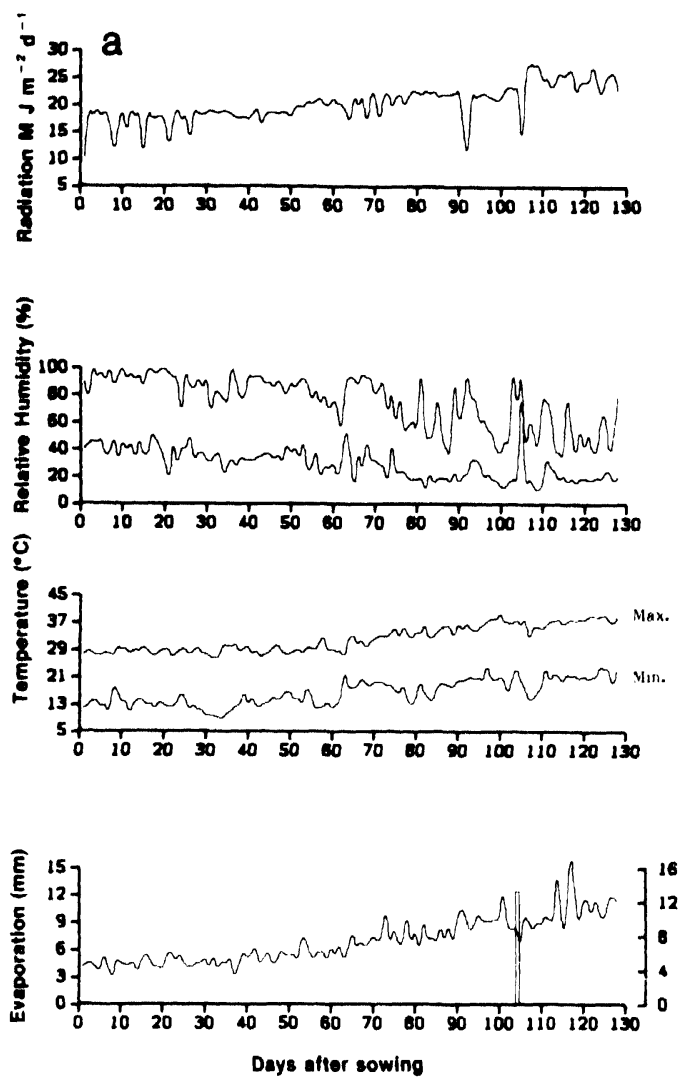

Fig. 1a, b, and c. Summary of weather data during the 1982-1983, 1984-1985, and 1985-1986 post-rainy seasons, respectively, at ICRISAT.

\section{RESULTS AND DISCUSSION}

Many factors influence the yield of a genotype and its adaptation to a given location and cropping season. Significant genotype $\times$ season interactions for peanut yields have been reported (ICRISAT, 1983). For this reason the results presented avoid disclosing the identity of individual genotypes, since relative performance might change in different environments in response to variation in temperature, photoperiod, and soil type. The major significance of the data from Exp. 1 is that a wide range of droughts were created without other environmental factors confounding the drought effects. Temperature, photoperiod, evaporative demands, and site were common to all treatments. Exp. 2 and 3 confirm the major responses observed in the first season.

Environmental data for the three experiments are presented in Fig. 1. In general, daily mean maximum temperatures increased steadily as the season progressed. This rise in air temperatures was associated with a decline in relative humidity and an increase in evaporative demand. In 1982-1983, there was little rainfall $(12.5 \mathrm{~mm}$ fell $20 \mathrm{~d}$ before harvest). This rainfall was added to irrigation received by individual plots while calculating water deficits in those treatments that were experiencing drought when the rains fell. However, in the other two experiments there was no rain during the period of drought treatments.
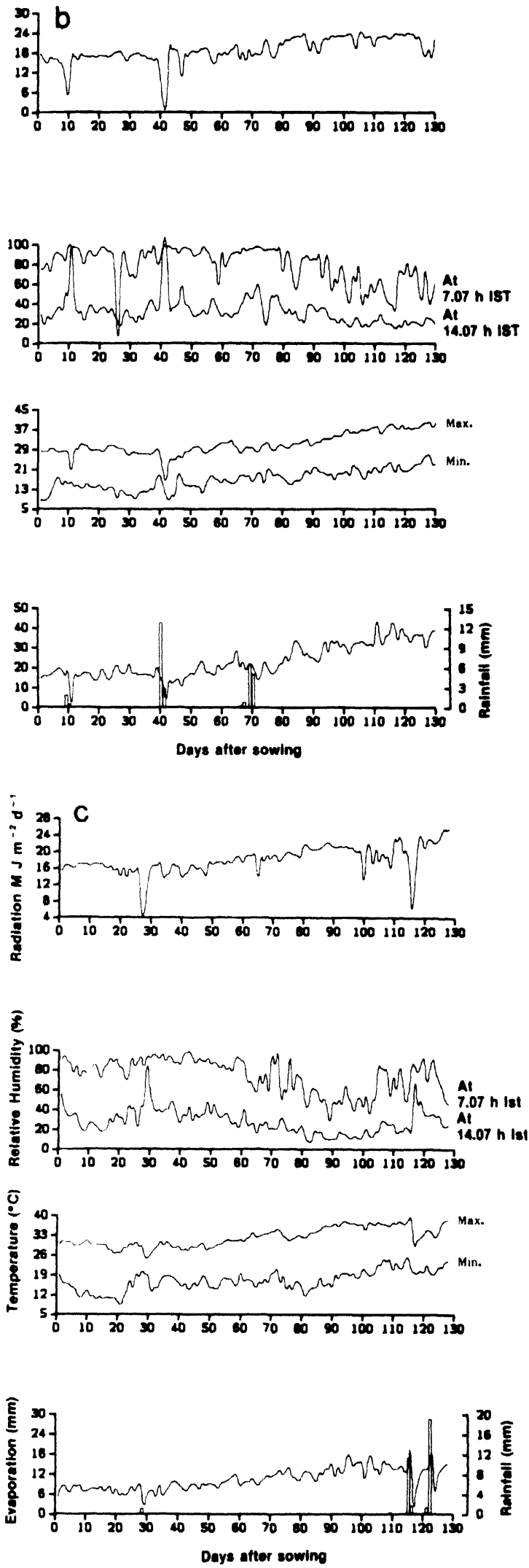
Yield potential of peanuts is determined by three attributes; crop growth rate, partitioning, and dura- tıon. In Exp. I, all genotypes started flowering between 35 and 37 DAS. These were all harvested on the same

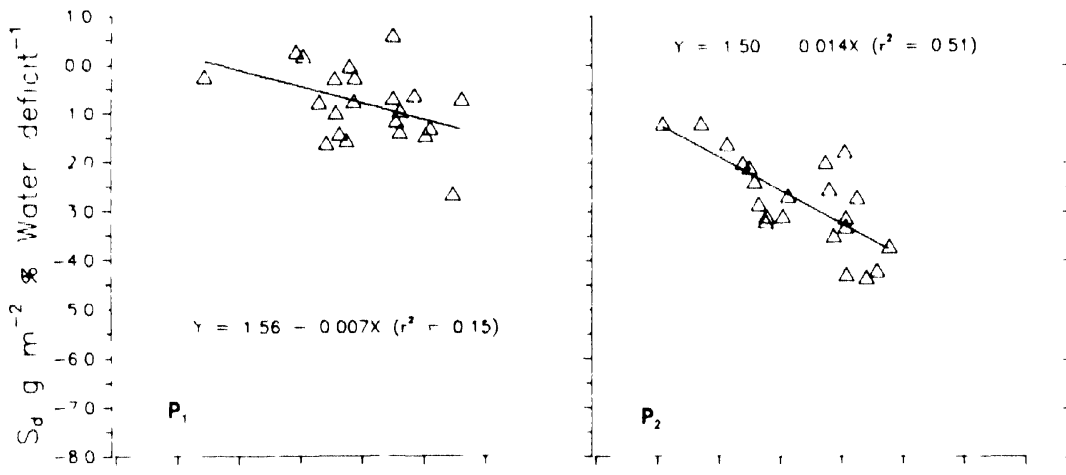

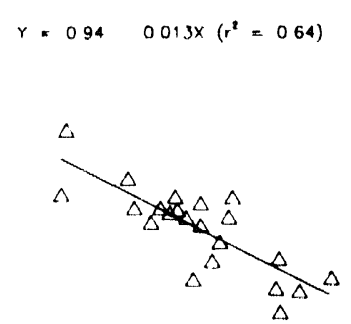

$\mathbf{P}_{3}$

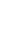

$Y 00030013 \times\left(r^{2}=091\right)$

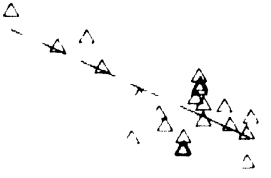

$Y \quad 16^{\prime} \quad 0011 \times\left(r^{2}-052\right)$

$P_{5}$

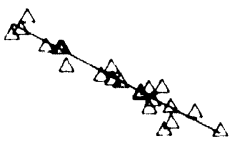

$\mathbf{P}_{\mathbf{8}}$

$Y=161 \quad 0016 \times\left(r^{2}=090\right)$

$Y=-030 \quad 0008 \times\left(r^{2}-038\right)$

$\triangle \triangle$

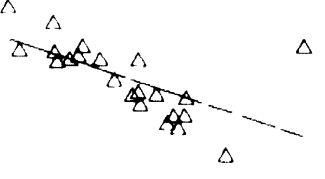

$P_{\mathbf{a}}$

$Y=130-0017 \times\left(r^{2}=092\right)$

$Y=015-0015 \times\left(r^{2}=082\right)$
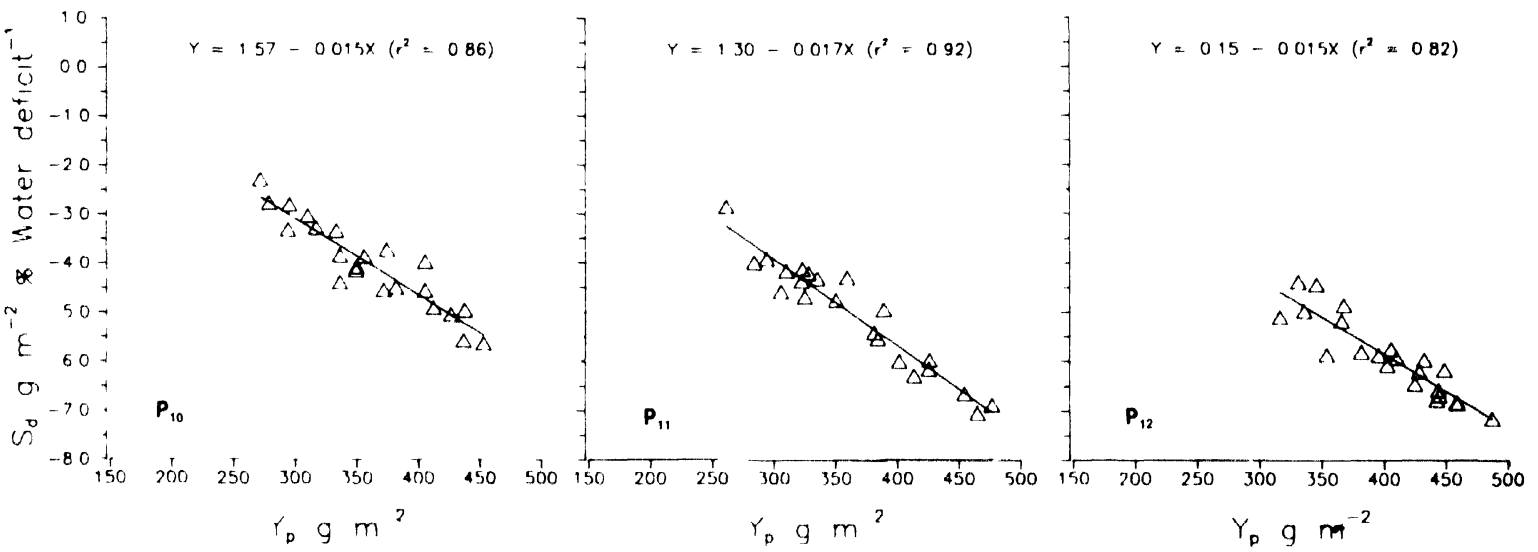

Fig. 2a. Relatıonship between genotypic sensituvity $\left(S_{d}\right)$ to drought pattern $P_{n}$ and pod yield potential $\left(Y_{p}\right)$ under irrigated conditions. (Patterns defined in Table 1. 
date, therefore the majority of pod yield potential variations were associated with differences in partitioning.

Peanuts have an indeterminate growth pattern, and early or midseason droughts tend to suspend development (Harris et al., 1988). This means that, given enough time after the release of drought stress, most genotypes can achieve reasonable yields. However, in rainfed agriculture, a midseason drought is not usually followed by infinite environmental resources (time and water), therefore we harvested all plots at the normal maturity date for the genotypes in unstressed conditions. Thus, for midseason drought treatments we were evaluating the speed of recovery from drought. However, since we have not used genotypes belonging to ssp. hypogaea in these experiments, the conclusions

Table 2. Analysis of drought sensitivity $\left(S_{\mathrm{d}}\right)$ and bivariate analysis of yield potential $\left(Y_{\mathrm{p}}\right)$ and $S_{\mathrm{d}}$ for 22 genotypes in 12 different drought patterns.

\begin{tabular}{ccc}
$\begin{array}{c}\text { Drought } \\
\text { patternt }\end{array}$ & $\left(S_{\mathrm{d}}\right)$ & $\begin{array}{c}\text { Variance ratio } \\
\text { bivariate analyses } Y_{\mathrm{p}} \text { and } S_{\mathrm{d}}\end{array}$ \\
\hline $\mathrm{P}_{1}$ & $\mathrm{NS}$ & $1.98^{* *}$ \\
$\mathrm{P}_{2}$ & $\mathrm{NS}$ & $2.97^{* *}$ \\
$\mathrm{P}_{3}$ & $* .37^{* *}$ \\
$\mathrm{P}_{4}$ & $*$ & $3.08^{* *}$ \\
$\mathrm{P}_{5}$ & $*$ & $3.69^{* *}$ \\
$\mathrm{P}_{6}$ & $\mathrm{NS}$ & $2.51^{* *}$ \\
$\mathrm{P}_{7}$ & $\mathrm{NS}$ & $1.90^{* *}$ \\
$\mathrm{P}_{\mathrm{B}}$ & $\mathrm{NS}$ & $1.62^{* *}$ \\
$\mathrm{P}_{9}$ & $*$ & $2.40^{* *}$ \\
$\mathrm{P}_{10}$ & $:$ & $2.64^{* *}$ \\
$\mathrm{P}_{11}$ & $*$ & $2.59^{* *}$ \\
$\mathrm{P}_{12}$ & $\mathrm{NS}$ & $1.94^{* *}$ \\
\end{tabular}

$\because$ Significant at $P<0.05$ and 0.01 , respectively. NS, not significant at $P$ $<0.05$.

† Drought patterns defined in Table 1 . derived in this study may apply to ssp. fastigiata (spanish and valencia types) only.

\section{Genotpyic Variability in Sensitivity to Drought}

In Exp. 1, genotypic variation in drought sensitivity $\left(S_{\mathrm{d}}\right)$ was statistically significant $(P<0.05)$ in six of the drought patterns. The bivariate analysis of $Y_{\mathrm{p}}$ and $S_{\mathrm{d}}$ was used because high $Y_{\mathrm{p}}$ allowed greater $S_{\mathrm{d}}$. This analysis indicated significant genotypic variability in all 12 drought patterns (Table 2). Bivariate analysis of variance across drought patterns (Table 3 ) showed that the genotype $\times$ drought pattern interaction was highly significant $(P<0.01)$.

\section{Relationship Between $S_{\mathrm{d}}$ and $\boldsymbol{Y}_{\mathrm{p}}$}

In Exp. 1, the correlation between $S_{\mathrm{d}}$ and $Y_{\mathrm{p}}$ was significantly negative in all drought patterns except $P_{1}$. Because of the varied association between $S_{\mathrm{d}}$ and $Y_{\mathrm{p}}$ for each drought pattern, linear regression relationships between these parameters were computed (Fig. 2). The percentage variation accounted for by the relationship between $S_{\mathrm{d}}$ and $Y_{\mathrm{n}}$ ranged from $15 \%$ in $\mathrm{P}_{1}$ to $92 \%$ in $P_{11}$.

These regression coefficients (slopes) were used to investigate the extent of yield loss in drought relative to the genotypic yield potential under irrigated conditions. For some drought patterns there was little variation in $S_{\mathrm{f}}$ other than that associated with yield potential, while for other patterns the association was weak. Thus, breeding for drought resistance combined with high yield potential seems feasible for some (early to midseason) droughts, while for most other drought patterns resistance requires a sacrifice of yield poten-

Table 3. Bivariate analysis of pod yield variance for genotype $\times$ drought pattern interaction.

\begin{tabular}{|c|c|c|c|c|c|c|}
\hline \multirow[b]{2}{*}{ Source } & \multirow[b]{2}{*}{ df } & \multicolumn{2}{|c|}{ Sum of squares } & \multirow[b]{2}{*}{ Sum of products } & \multirow[b]{2}{*}{ Wilk's Criterion } & \multirow[b]{2}{*}{$F$ value } \\
\hline & & $\ln t$ & Slope & & & \\
\hline $\begin{array}{l}\text { Genotype } \\
\text { Genotype } \times \text { Pattern } \\
\text { Error }\end{array}$ & $\begin{array}{r}21 \\
231 \\
504\end{array}$ & $\begin{array}{r}1373065 \\
769185 \\
1660309\end{array}$ & $\begin{array}{l}209 \\
341 \\
603\end{array}$ & $\begin{array}{r}15870 \\
-12806 \\
-26717\end{array}$ & $\begin{array}{l}0.4416 \\
0.3936\end{array}$ & $\begin{array}{r}12.70^{*} * \\
1.30^{*}\end{array}$ \\
\hline
\end{tabular}

** Statistically significant at $P<0.01$.

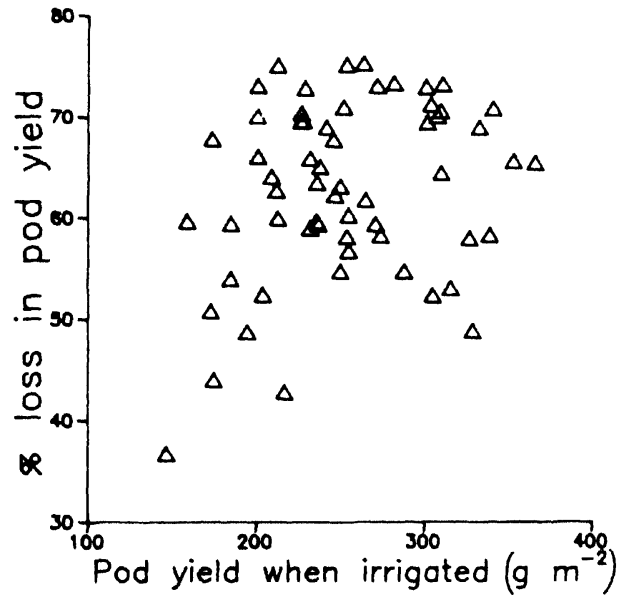

Fig. 3. Relationship between yield loss due to midseason drought and pod yield potential under irrigated conditions in 60 peanut genotypes.

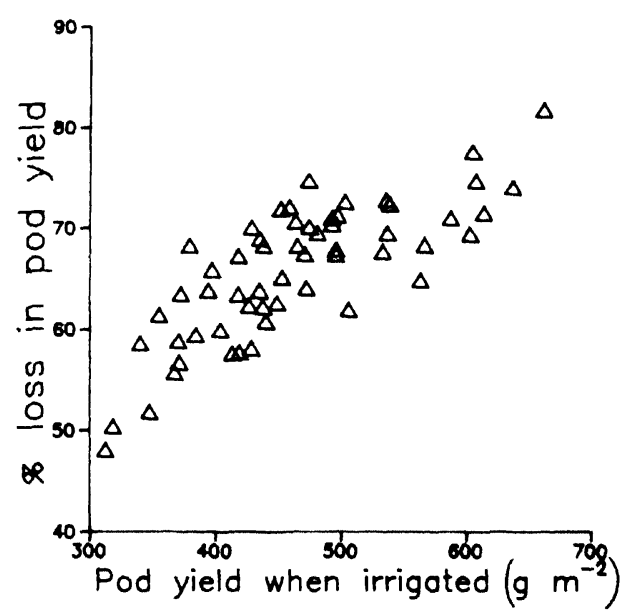

Fig. 4. Relationship between yield loss due to end-of-season drought and pod yield potential under irrigated conditions in 64 peanut genotypes. 
Table 4. Grouping of drought patterns based on similarity in slopes of regressions between $S_{\mathrm{d}}$ and $\boldsymbol{Y}_{\mathrm{p}}$.

\begin{tabular}{cccccccc}
\hline \multicolumn{2}{c}{ Group 1 } & & \multicolumn{2}{c}{ Group 2 } & & \multicolumn{2}{c}{ Group 3 } \\
\cline { 1 - 2 } \cline { 7 - 8 } \cline { 6 - 7 } Pattern† & Slope & & Pattern† & Slope & & Pattern $\dagger$ & Slope \\
\hline$P_{11}$ & -0.0174 & & $P_{2}$ & -0.0136 & & $P_{8}$ & -0.0080 \\
$P_{7}$ & -0.0168 & & $P_{4}$ & -0.0128 & & $P_{1}$ & -0.0067 \\
$P_{9}$ & -0.0159 & & $P_{3}$ & -0.0127 & & & \\
$P_{10}$ & -0.0155 & & $P_{6}$ & -0.0127 & & \\
$P_{12}$ & -0.0145 & & $P_{3}$ & -0.0114 & & \\
\hline
\end{tabular}

$\uparrow$ Patterns defined in Table 1.

tial in the good environments. In the drought patterns in which $S_{d}$ increased most rapidly with $Y_{p}$, the relationship between these parameters tended to be strongest (Fig. 2). The exception to this was in partern $\mathrm{P}_{2}$ (midseason drought), indicating that breeding for yield potential combined with tolerance is both possible and most profitable. These results were supported by Exp. 2 and 3 , in which a wider range of peanut germplasm was subjected to midseason and end-of-season droughts. In Exp. 2, 60 genotypes were subjected to a midseason drought similar to $P_{5}$ of Exp. 1. No significant correlation existed between percent yield loss due to drought and yield potential (Fig. 3). In Exp. 3, the relationship for the 64 genotpyes in drought similar to $\mathrm{P}_{4}$ was significant (Fig. 4).

The proportion of yield loss attributable to $Y_{\mathrm{p}}$ also depended on when the drought ended relative to the harvest date (Fig. 5). The association of $S_{\mathrm{d}}$ with $Y_{\mathrm{p}}$ was usually greater when the drought continued until harvest, but became progressively weaker as the interval between the last day of drought and harvest increased. Using Mahalanobis' $D^{2}$ criterion, the drought patterns were arranged in three groups on the basis of similarity of slopes of the regressions between $S_{\mathrm{d}}$ and $Y_{\mathrm{p}}$ (Table 4).

The effectiveness of this grouping in establishing the similarity of regression coefficients within groups was tested by further partitioning the genotype $X$ pattern interaction into interactions due to genotype $X$ group and genotype $X$ patterns within each group (Table 5). The interation between genotypes and groups was highly significant, while the interaction between genotype and drought pattern was only significant $(P<$ 0.05 ) in the case of Group 2.

Group 1 included drought patterns in which yield potential resulted in the greatest sensitivity to drought. These patterns were the multiple droughts (except $\mathrm{P}_{8}$ ) and the long-term drought over the whole season $\left(P_{7}\right)$. The only pattern in this group in which drought did not span the pod filling phase was $P_{10}$. It was interesting that a long, early drought with a single, short release of drought (simulation of a single rain) resulted in a very different response in $P_{10}$ relative to $P_{5}$ (same

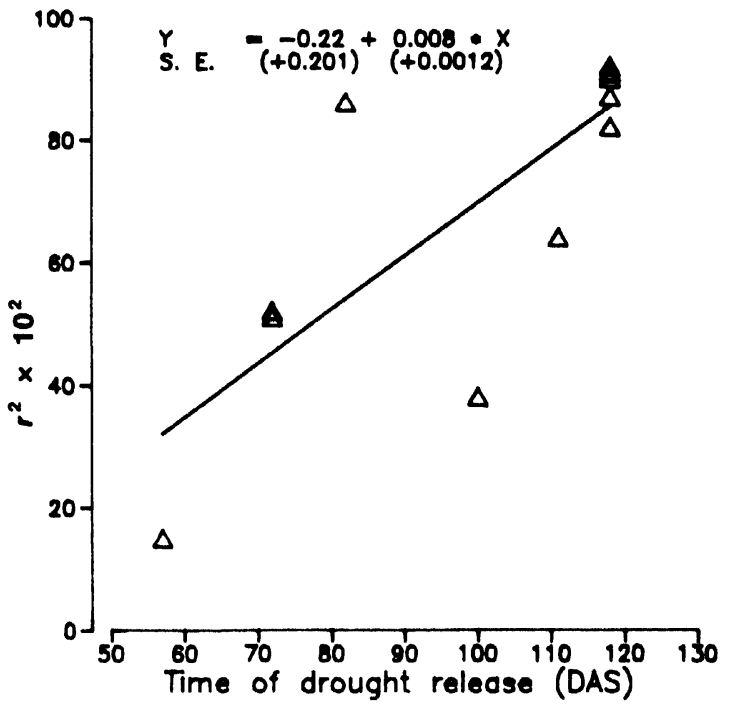

Fig. 5. Relationship between time of release of drought and the amount of variation in drought sensitivity that is accounted for by the yield potential of genotypes.

timing and duration, but without the short return to irrigated conditions). Recovery responses, which were initiated by the irrigation, could not be sustained in $P_{10}$ due to the reoccurrence of drought; while in $P_{5}$. crop was able to initiate the recovery and sustain this process due to a long-term return to nonstress conditions.

In Group 3 (where $S_{\mathrm{d}}$ and $Y_{\mathrm{p}}$ were poorly related), both patterns had an early drought followed by long periods of adequate irrigation. The early drought apparently provided some protection against the later drought in the case of $P_{8}$. Where crops can be started on either a single irrigation or with a pre-monsoon shower, it seems that reasonable protection against further drought can be achieved without sacrificing yield potential. This strategy provides the added benefit of increasing the season length available to crops or increasing the probabilities of escaping end-of-season drought.

In environments prone to multiple droughts (Group 1 based on $S_{\mathrm{d}}$ ), yield losses will be greater for genotypes with higher yield potential. If farmers without irrigation adopt genotypes that have high yield potential (associated with greater drought sensitivity), yields will be less stable than if genotypes with lower yield potential were chosen. The choice of genotype should, therefore, take into account the probability with which Group I type droughts occur. There seems particular merit in modeling the yields from both drought sen-

Table 5. Partitioning of genotype $\times$ drought pattern interaction.

\begin{tabular}{|c|c|c|c|c|c|c|}
\hline \multirow[b]{2}{*}{ Source } & \multirow[b]{2}{*}{ df } & \multicolumn{2}{|c|}{ Sum of Squares } & \multirow[b]{2}{*}{ Sum of products } & \multirow[b]{2}{*}{ Wilk's criterion } & \multirow[b]{2}{*}{$F$ value } \\
\hline & & Int & Slope & & & \\
\hline $\begin{array}{l}\text { Genotype } \times \text { Group } 1 \dagger \\
\text { Genotype } \times \text { Group } 2 \\
\text { Genotype } \times \text { Group } 3 \\
\text { Genotype } \times \text { groups } \\
\text { Error }\end{array}$ & $\begin{array}{r}84 \\
84 \\
21 \\
42 \\
504\end{array}$ & $\begin{array}{r}284731 \\
245907 \\
92270 \\
146276 \\
1660309\end{array}$ & $\begin{array}{r}104 \\
131 \\
26 \\
80 \\
603\end{array}$ & $\begin{array}{r}-5088 \\
-4552 \\
-1046 \\
-2122 \\
-26717\end{array}$ & $\begin{array}{l}0.7918 \\
0.6828 \\
0.8668 \\
0.7139\end{array}$ & $\begin{array}{l}0.75 N^{N S} \\
1.27^{*} \\
1.77 N S \\
2.55^{* *}\end{array}$ \\
\hline
\end{tabular}

*** Significant at $P<0.05$ and 0.01 , respectively. NS, not significant at $P=0.05$.

$\dagger$ Groups defined in Table 4. 
sitive-high potential and drought resistant-low potential genotypes using historic weather data as a basis for genotype recommendations (Bailey, 1988). As a practical breeding consideration, it seems possible to predict $S_{\mathrm{d}}$ in these droughts from the yield potential in unstressed conditions.

In areas where end-of-season droughts occur, the best strategy may be to select for earliness. This will maximize the probability of escape from this type of drought. However, yield potential is also influenced by the crop growth duration, so a compromise between yield potential (duration) and carliness (escape) needs to be achieved. It is also possible in these environments that the genotypes with high yield potential (with high sensitivity to drought) still would have higher yields in drought conditions than moderateyielding lines with low sensitivity to drought.

The results indicate that for those drought patterns with a weak correlation between $S_{\mathrm{d}}$ and $Y_{\mathrm{p}}$, as it was for early and midseason droughts, it may be possible to identify genotpypes with both moderate yield potential and lower drought sensitivity (a conclusion supported by the significant pattern $X$ genotype interaction within group 2). In such cases, selection in well-watered environments is not likely to identify genotypes that have lower sensitivity to drought. This phenomenon needs further study, and selection procedures to identify such genotypes need to be further developed.

\section{ACKNOWLEDGMENTS}

The authors wish to thank Drs. F.R. Bidinger and J.M. Peacock for valuable discussions during the course of pre- paring this manuscript, and Messrs. K. Eshwar, D.M Krishna, and M. Krishnaiah for their assistance in conducting the experiment.

\section{REFERENCES}

Bailey. E. 1988. The use of risk analysis in the evaluation of genotype performance. Ph.D. Thesis. Cornell Univ.. Ithaca, New York (Diss. Abstr. 88-21201).

Billaz, R., and R. Ochs. 1961. Stades de sensibilite de l'arachide a la secheresse. Oleagineux 16:605-611

Boote, K.J., J.R. Stansell. A.M. Schubert and J.F. Stone. 1982. Irrigation, water use, and water relations. p. 164-205. In H.E. Pattee and C.T. Young (ed.) Peanut science and technology. Am. Peanut Res. Educ. Soc., Inc, Yoakum, TX

Gibbons, R.W. 1980. The ICRISAT Groundnut Program. p. 12-16. In Proc. Int. Workshop on Groundnuts. Int. Crops Res. Inst. Semi-Arid Tropics, 13-17 Oct. 1980. ICRISAT, Patancheru, A.P India.

Hanks. R.J., J. Keller, V.P. Rasmussen, and G.D. Wilson. 1976. Line-source sprinkler for continuous variable irrigation crop production studies. Soil Sci. Soc. Am. J. 40:426-429.

Harris, D., R.B. Mathews, R.C. Nageswara Rao, and J.H. Williams. 1988. The Physiological basis for yield differences between fou genotypes of groundnuts (Arachis hypogaea) in response to drought. III. Developmental processes. Exp. Agric. 24:215-226.

ICRISAT 1983. Yield physiology. p. 211-213. In Annual Report 1982. ICRISAT (International Crops Research Institute for the Semi-Arid Tropics), Patancheru, A.P. India.

Krantz, B.A., J. Kampen, and S.M. Virmani. 1978. Soil and water conservation and utilization for increased production in the SemiArid Tropics. p. 327. In Proc. 11 th Int. Soc. Soil Sci. Congress of Soil Science, Edmonton, Alberta, Canada.

Nageswara Rao, R.C. Sardar Singh., M.V.K. Sivakumar., K.L. Srivastava, and J.H. Williams. 1985. Effect of water deficit at different growth phases of peanut. I. Yield responses. Agron. J. $77 \cdot 782-786$

Pallas, J.F., Jr., J.R. Stansell, and T.G. Koske. 1979. Effects of drought on Florunner peanuts. Agron. J. 71:853-858.

Rao. C.R. 1974. Pooling of estimates. p. 555. In Linear statistical inference and its application. John Wiley and Sons. Inc., New York. 